\title{
A Propósito das Novas Massas Atómicas Relativas Médias de Alguns Elementos Químicos
}

\author{
Adélio A. S. C. Machado, João Cardoso, Joaquim Marçalo, José Alberto L. Costa, Maria Clara \\ Magalhães:, Maria Helena Garcia, Olivier Pellegrino, Osvaldo A. Serra e Roberto B. Faria
}

\begin{abstract}
A revisão bianual feita pela Comissão de Abundâncias Isotopicas e Massas Atómicas (CIAAW) da Divisão de Unica Inorgânica da União Internacional de Química Pura e Aplicada (IUPAC), referente a 2009, contém uma inovação na apresentação das massas atómicas relativas médias de dez elementos. Para o hidrogénio, lítio, boro, carbono, nitrogénio, oxigénio, silício, enxofre, cloro e tálio, a massa atómica relativa média é apresentada como um intervalo de valores e não na forma de um valor com a respetiva incerteza associada. Esta nova apresentação das massas atómicas relativas médias corresponde formalmente a uma mudança de paradigma de grande significado, não só para a química, como para a ciência em geral. A grandeza passa de ser expressa por um valor estatisticamente provável dentro de um limite definido de incerteza, para ser expressa por um conjunto de valores dentro de um intervalo de incerteza não controlado estatisticamente, sendo qualquer um possível. Neste artigo chama-se a atenção para as razões que justificaram esta mudança, bem como para as dificuldades que pode implicar na prática da química e no seu ensino a nível elementar.
\end{abstract}

\begin{abstract}
A Tabela Periódica dos Elementos Químicos publicada no número 123 do Boletim da Sociedade Portuguesa de Química contém alterações nas massas atómicas relativas médias ${ }^{1}$ de onze elementos, em relação à que vigorava anteriormente, em consequência da última revisão bianual feita pela Comissão de Abundâncias Isotópicas e Massas Atómicas (CIAAW) da Divisão de Química Inorgânica da União Internacional de Química Pura e Aplicada (IUPAC), referente a 2009 [1].
\end{abstract}

Esta Comissão costuma publicar, no Pure and Applied Chemistry, o periódico mensal oficial da IUPAC, a revisão bienal das massas atómicas relativas médias dos elementos químicos. Até agora, as sucessivas revisões têm consistido apenas em mudanças de valores, feitas com base em novos estudos de determinação de massas atómicas relativas dos isótopos e da composição isotópica de amostras naturais contendo os elementos cujos valores são revistos. A última revisão, publicada por Wieser e Coplen em 2011 [1], inclui uma inovação: para alguns elementos o valor (com a incerteza associada) da massa atómica relativa média foi substituído por um intervalo de valores. Este artigo tem como objetivo chamar a atenção para este facto e para as razões que o jus-

\footnotetext{
·E-mail:mclara@ua.pt
}

tificaram, bem como para as dificuldades que pode significar na prática da química e, em particular, no seu ensino a nível elementar.

\section{As MUDANÇAS E SUA RAZÃO DE SER}

Na referida revisão [1], foram introduzidas as massas atómicas relativas médias de dez elementos químicos (Tabela 1) sob a forma de intervalos de valores (a massa atómica relativa média do germânio também foi ligeiramente alterada passando de $72,63(1)$ para $72,64(1)$, no estilo das revisões anteriores). As massas atómicas relativas médias destes elementos, que possuem mais de um isótopo estável (ver adiante), são obtidas tendo em conta as abundâncias isotópicas relativas em diferentes materiais naturais, mas apresentam diferenças maiores que a incerteza de medição associada a cada determinação.

Deste modo, a expressão da massa atómica relativa média como uma média dos valores de massas atómicas relativas dos isótopos ponderados pelas respetivas frações molares de ocorrência natural, usada invariavelmente no passado, não tem significado. Nestas situações, em que ocorrem amostras naturais com massas atómicas relativas médias fora do intervalo "Valor \pm Incerteza experimental", a CIAAW optou por fornecer um intervalo de massas atómicas relativas mé- dias para os elementos. As Figuras 1 e 2, representam, respetivamente, a variação da massa atómica relativa média do silício e do lítio com a composição isotópica (exemplificando-se aqui com os isótopos Si-30 e Li-7) para alguns materiais contendo estes elementos. Como se pode notar, as massas atómicas relativas médias do silício e do lítio não são constantes da natureza, mas dependem da fonte do material, havendo valores que não estavam incluídos nos limites estabelecidos pelos valores publicados até 2007 [1]. A incerteza-padrão associada ao valor da massa atómica relativa média, calculado a partir da "melhor medição" de abundância isotópica, é, para o silício, cerca de quarenta vezes menor que a incerteza da massa atómica relativa média publicada em 2007. Para o lítio, esta incerteza é cerca de oito vezes menor [1]

Para se compreender melhor a necessidade de mudança na apresentação das massas atómicas relativas médias dos elementos constantes da Tabela 1, a Figura 3 exemplifica o caso das variações das massas atómicas relativas médias de elementos em materiais terrestres naturais cujos valores não excedem a incerteza da massa atómica relativa média, através da variação da massa atómica relativa média do ferro com a composição isotópica (representada aqui pelo seu isótopo $\mathrm{Fe}-56$ ) [1] 
Tabela 1 - Massas atómicas relativas médias e seus valores convencionais para os dez elementos que apresentam as massas atómicas relativas médias como intervalos de valores

\begin{tabular}{|l|c|c|c|}
\hline Nome do elemento & $\begin{array}{c}\text { Número atómico } \\
\text { do elemento }\end{array}$ & $\begin{array}{c}\text { Massa atómica relativa } \\
\text { média }\end{array}$ & $\begin{array}{c}\text { Massa atómica relativa } \\
\text { média convencional }\end{array}$ \\
\hline hidrogénio & 1 & {$[1,00784 ; 1,00811]$} & 1,008 \\
\hline lítio & 3 & {$[6,938 ; 6,997]$} & 6,94 \\
\hline boro & 5 & {$[10,806 ; 10,821]$} & 10,81 \\
\hline carbono & 6 & {$[12,0096 ; 12,0116]$} & 12,011 \\
\hline nitrogénio & 7 & {$[14,00643 ; 14,00728]$} & 14,007 \\
\hline oxigénio & 8 & {$[15,99903 ; 15,99977]$} & 15,999 \\
\hline silício & 14 & {$[28,084 ; 28,086]$} & 28,085 \\
\hline enxofre & 16 & {$[32,059 ; 32,076]$} & 32,06 \\
\hline cloro & 17 & {$[35,446 ; 35,457]$} & 35,45 \\
\hline tálio & 81 & {$[204,382 ; 204,385]$} & 204,38 \\
\hline
\end{tabular}

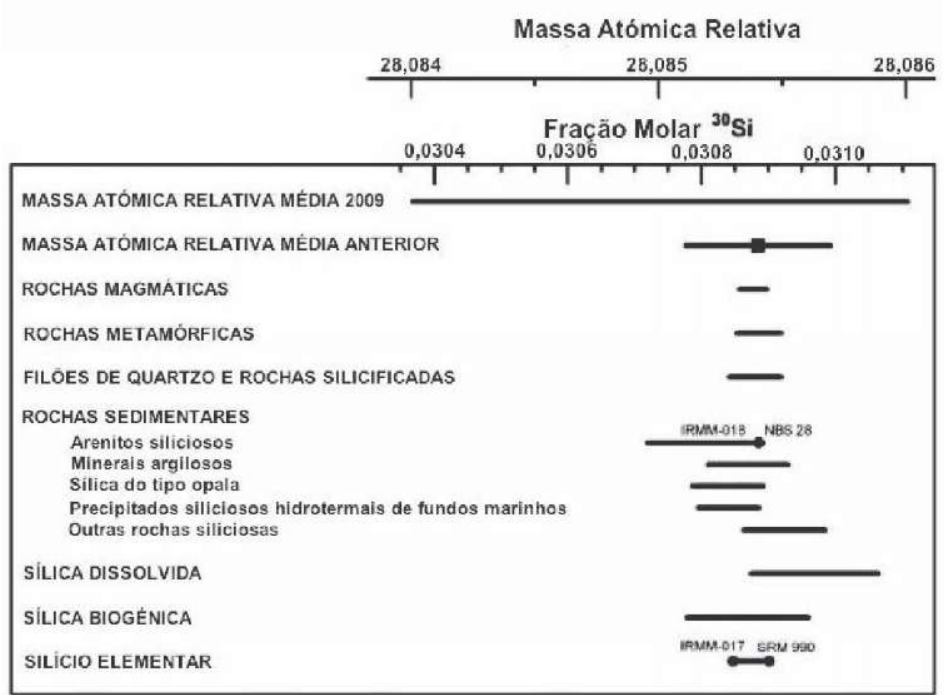

Figura 1 - Variação da massa atómica relativa média do silício com a composição no seu isótopo Si-30 de alguns materiais naturais (tradução e adaptação da Figura 8 da referência [1]). Os materiais de referência isotópica ${ }^{2}$ estão representados por um círculo negro cheio

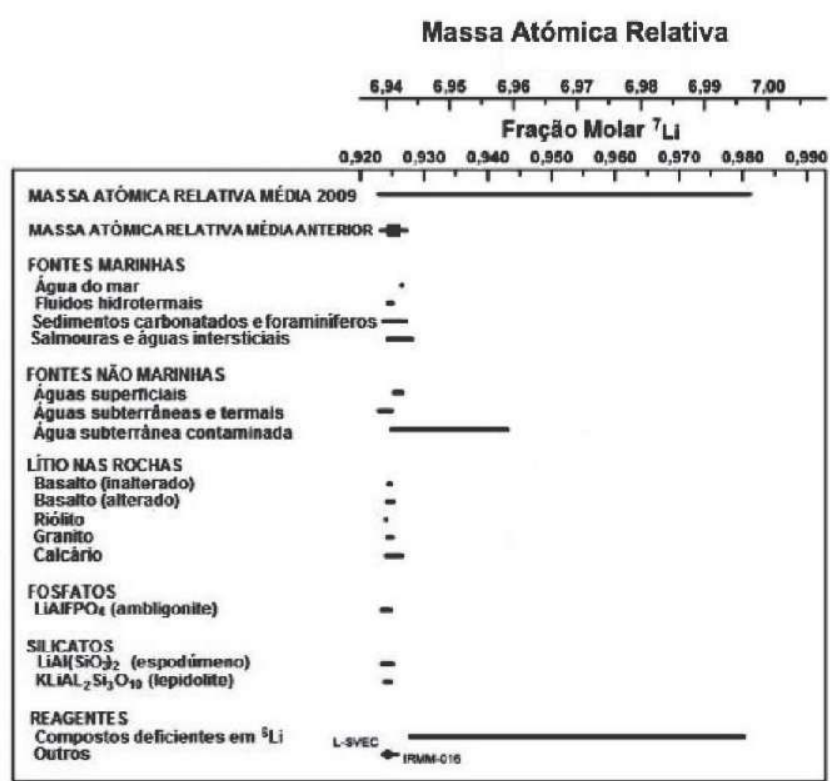

Figura 2 - Variação da massa atómica relativa média do lítio com a composição no seu isótopo Li-7 de alguns materiais naturais (tradução e adaptação da Figura 4 da referência [1]). Os materiais de referência isotópica² estão representados por um círculo negro cheio
O CONCEITO DE MASSA ATÓMICA RELATIVA MÉDIA

A massa atómica relativa média de um dado elemento é usada, convencionalmente, como o valor recomendado da massa atómica relativa desse elemento, revisto bianualmente pela CIAAW, e aplicável, com um nível de confiança elevado, aos elementos existentes em qualquer amostra "normal" [2]. Segundo a CIAAW, uma amostra "normal" é um material de origem terrestre, "... uma fonte razoavelmente possivel deste elemento ou dos seus compostos para o comércio, a indústria ou a ciência; o material não é estudado por causa de qualquer anomalia extraordinária e a sua composição isotópica não se tem alterado significativamente num período geológico curto." [1].

Para o cálculo do "melhor valor" da massa atómica relativa média de um dado elemento químico, a CIAAW consulta os vários trabalhos publicados até essa altura, com os valores das abundâncias isotópicas do elemento existentes em várias fontes, escolhendo os trabalhos de confiança. Para ser considerado para avaliação, o trabalho tem que cumprir um conjunto de requisitos nos quais se incluem uma boa caracterização de uma amostra do material, que deve ser representativa, e resultados de medição com incertezas-padrão combinadas baixas. Por exemplo, na determinação da massa atómica relativa média do silício (Figura 1), determinou-se a composição isotópica do silício em rochas magmáticas, rochas sedimentares (arenitos siliciosos, minerais argilosos e outras rochas contendo silício), rochas metamórficas, filões de quartzo, sílica dissolvida, sílica biogénica, entre outros materiais.

A massa atómica relativa média de um elemento " $E$ ", $A_{r}(E)$, numa dada amostra "P" é determinada a partir das massas atómicas relativas dos isótopos estáveis desse elemento e das correspondentes abundâncias relativas de cada um desses isótopos que foram medidas nessa amostra. A massa atómica relativa média de um elemento que tenha mais do que um isótopo estável, na amostra "P", é dada pelo somatório dos produtos da 


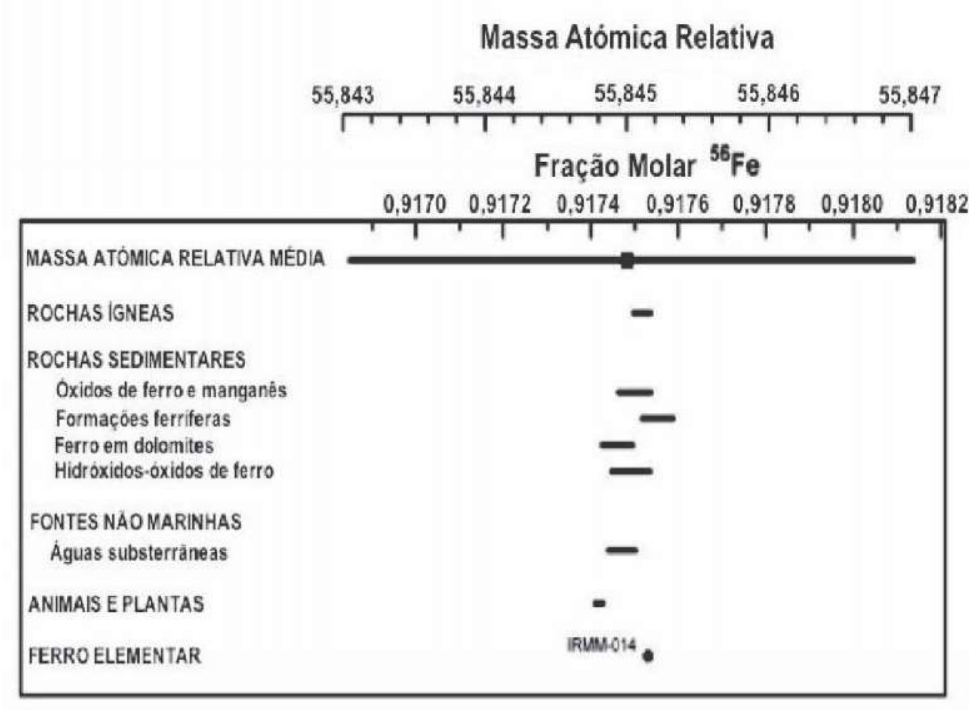

Figura 3 - Variação da massa atómica relativa média do ferro com a composição no seu isótopo Fe-56 de alguns materiais naturais (tradução e adaptação da Figura 1 da referência [1]). $\mathrm{O}$ material de referência isotópica ${ }^{2}$ está representado por um círculo negro cheio

massa atómica relativa de cada isótopo $\left[A_{r}(' E)\right]$ pela sua fração molar $[x(' E)]$ nessa amostra, traduzido na relação:

$\left.A_{\mathrm{r}}(\mathrm{E})_{\mathrm{P}}=\sum_{\mathrm{i}}\left[x\left({ }^{\mathrm{i}} \mathrm{E}\right) A_{\mathrm{r}}{ }^{(} \mathrm{E}\right)\right]$

Neste somatório, consideram-se todos os isótopos estáveis do elemento "E" encontrados na amostra [1]. A incerteza-padrão associada à massa atómica relativa média dos elementos que contêm mais do que um isótopo estável decorre não só das incertezas-padrão dos resultados das medições das massas isotópicas, mas também da variação na composição isotópica dos materiais "normais".

Para a determinação das massas atómicas relativas médias, a CIAAW definiu como isótopo estável todo aquele que tenha um período de semidesintegração ${ }^{3}$ superior a $1 \times 10^{10}$ anos [3]. A aplicação desta definição estabeleceu a existência dos seguintes elementos químicos com um único isótopo: berílio, flúor, sódio, alumínio, fósforo, escândio, manganês, cobalto, arsénio, ítrio, nióbio, ródio, iodo, césio, praseodímio, térbio, hólmio, túlio, ouro, bismuto e tório [3]. Para estes elementos, a massa atómica relativa média é igual à massa atómica relativa do seu isótopo estável e a incerteza-padrão associada ao seu valor resulta apenas da incerteza na medição da massa atómica relativa desse isótopo. Para estes vinte e um elementos com um único isótopo estável, a massa atómica relativa média, independente do material, é uma constante da natureza

Para os elementos que não têm qualquer isótopo estável, não se pode calcular massas atómicas relativas médias, pelo que nenhum valor é apresentado na Tabela Periódica dos Elementos. Esse é o caso do tecnécio, do promécio e dos elementos químicos com número atómico igual ou superior a 84 (polónio), com exceção do tório, do protactínio e do urânio. Estes três elementos têm uma composição isotópica terrestre característica e, para cada um deles, há um valor tabelado de massa atómica relativa média [1]. Por exemplo, a abundância (em fração molar) dos isótopos terrestres naturais para o urânio é de $0,992742(10)$ para o isótopo U-238, de $0,007204(6)$ para o isótopo U-235 e de 0,000 054(5) para o isótopo U-234. No caso do tório, utiliza-se a massa atómica relativa do isótopo Th232 [4].

Para os elementos com mais do que um isótopo estável, em que a diferença dos valores da massa atómica relativa média nos materiais terrestres naturais não excede a incerteza-padrão da massa atómica relativa média derivada da "melhor medição" das abundâncias isotópicas, a massa atómica relativa média apresenta um valor único com uma incerteza asso- ciada, e o intervalo "Valor \pm Incerteza" engloba as massas atómicas relativas médias encontradas nos materiais terrestres naturais (Figura 3 ). No entanto, nem sempre se verifica esta situação, já que os valores das massas atómicas relativas médias calculados a partir das variações publicadas nas composições isotópicas podem distribuir-se por um intervalo relativamente grande.

Para os elementos com mais do que um isótopo estável, em que a variação dos valores da massa atómica relativa média nos materiais terrestres naturais excede a incerteza-padrão da massa atómica relativa média derivada da "melhor medição" das abundâncias isotópicas (determinada a partir de materiais de referência), os limites superior e inferior da massa atómica relativa média determinada definem o intervalo agora apresentado pela CIAAW para expressar a massa atómica relativa média do elemento. Para o estabelecimento dos valores limites deste intervalo, são usadas incertezas-padrão assimétricas associadas à "massa atómica relativa média", em vez de incertezas-padrão simétricas tradicionais.

A ESCOLHA DO VALOR DE MASSA ATÓMICA RELATIVA MÉDIA PARA FINS PRÁTICOS

A expressão de massas atómicas relativas médias como um intervalo põe desde logo dois problemas. Por um lado, a realização expedita de cálculos estequiométricos exige um valor e não um intervalo. Por outro lado, apresentar intervalos para certos elementos, quando se introduz aos estudantes dos ensinos básico e secundário o conceito de massa atómica relativa média, parece ser problemático, sendo no mínimo confuso.

Com vista a resolver o primeiro problema, para os utilizadores do comércio e da indústria, a CIAAW incluiu na revisão de 2009 [1] valores convencionais $^{4}$ das massas atómicas relativas médias de elementos com mais de um isótopo estável cuja variação da abundância natural terrestre é maior que a incerteza-padrão da massa atómica relativa média. Estes valores convencionais, apresentados na Tabela 1, possuem um número de al- 
garismos significativos menor que os indicados nos valores extremos dos intervalos (com exceção do valor para o silício), não têm incertezas associadas e foram selecionados de modo que a maioria ou a totalidade da variação da massa atómica relativa média natural terrestre esteja incluída dentro de um intervalo com mais ou menos uma unidade do último algarismo significativo. Ao comparar, na Tabela 1 , os valores das massas atómicas relativas médias convencionais com os valores dos extremos das massas atómicas relativas médias, verifica-se que o lítio é o único elemento em que o extremo mais elevado está bastante afastado do valor convencional. Por meio da Figura 2, que representa a variação da massa atómica do lítio com a composição no seu isótopo Li-7, é fácil de compreender a escolha feita para o valor convencional do lítio. 0 intervalo $[6,93 ; 6,95]$ inclui a composição isotópica da maioria dos materiais terrestres onde tem sido analisada a composição em lítio. Já para o silício, a sua massa atómica relativa média convencional é 28,085 e pode ver-se, através da Figura 1, que a mesma foi selecionada de modo a que o intervalo $[28,084 ; 28,086]$ contenha todos os materiais terrestres onde tem sido analisada a composição isotópica do silício, que, neste caso, coincide com o intervalo da massa atómica média relativa. O intervalo de massas atómicas relativas médias proposto para cada um dos dez elementos tem em consideração o contributo de todos os isótopos estáveis de cada elemento que são, no caso do silício, o Si-28, o Si-29 e o Si-30, com a composição isotópica média (em fração molar) de, respectivamente, 0,922 23(19), $0,04685(8)$ e 0,030 92(11) [4].

Quanto à questão das dificuldades que os alunos possam sentir na introdução ao tema das massas atómicas relativas dos elementos com intervalos de valores e não um valor com a incerteza associada, caberá aos professores e outros formadores encontrar e utilizar as metodologias que considerarem mais adequadas.

\section{CONCLUSÕES}

Para os dez elementos químicos cujas massas atómicas relativas mé- dias são agora apresentadas sob a forma de um intervalo, a massa atómica relativa média do elemento não deve ser calculada como a média dos valores limites do intervalo mais ou menos a metade da diferença entre estes valores limites [1]. Uma vez que o intervalo contém todos os valores conhecidos de combinações isotópicas de ocorrência natural (Figuras 1 e 2), qualquer valor de massa atómica relativa média contido nesse intervalo pode ser legitimamente usado Fica ao critério do utilizador a escolha do valor a usar, desde que este seja um valor dentro do intervalo de valores definido e que se apresente uma fundamentação adequada para essa escolha, o que pode não ser simples.

Para que se possa fazer uma escoIha fundamentada do valor de massa atómica relativa média a utilizar é necessário conhecer a origem dos materiais que serão utilizados. Isto significa que, no futuro, idealmente, cada produto químico deverá conter no rótulo informações sobre a origem das matérias-primas utilizadas na sua produção ou os valores de massas atómicas relativas médias a utilizar para os cálculos envolvendo aquele material. Se há atividades em que a questão de rastrear a origem de um dado material não se coloca, como na maioria das atividades ligadas ao ensino da química, para outras atividades, com necessidade de maior rigor, a escolha da massa atómica relativa média a ser utilizada dependerá do conhecimento da origem e de toda a história da manipulação do material que se vai utilizar. Nas atividades ligadas ao ensino, no sentido de se interiorizar este novo paradigma de abordagem da química, pode-se estimular a utilização de valores diferentes dentro da gama de intervalo definido para cada elemento, mas será preciso avaliar os impactos desta atitude na compreensão do conceito pelos alunos, o alcance que pode atingir, etc.. Fica aqui um desafio aos professores de química para que pensem nesta nova situação, caracterizem os problemas que levanta e avancem com propostas de soluções. O uso de um intervalo de valores para indicar a massa atómica relativa média para os dez elementos da Tabela 1 corresponde a uma mudança de paradigma de grande significado, não só para o entendimento da química, como da ciência em geral. É um erro comum considerar que a ciência e os cientistas podem obter sempre respostas inequívocas para as questões postas na interpretação dos fenómenos da natureza e valores mais exatos para as suas constantes. Os intervalos de valores de massas atómicas relativas médias recomendados pela IUPAC deixam evidente que ocorrem situações em que não existe uma resposta certa ou exata, mas sim um limite natural de confiança que não é possível ultrapassar, mesmo que se melhorem os equipamentos e os procedimentos experimentais. No presente caso, a progressiva melhoria destes permitiu fazer as determinações de massas atómicas relativas dos isótopos e de composições isotópicas com precisões cada vez maiores, o que acabou por evidenciar que, na natureza, estas últimas são mais dispersas do que se admitia até agora - a natureza é mais complexa do que os cientistas aceitavam com base na hipótese da máxima simplicidade, a velha lâmina (navalha ou faca) de Occam (a lei da parcimónia).

A mudança de paradigma implica passar de um valor estatisticamente provável dentro de um limite definido de incerteza para qualquer valor possível dentro de um intervalo de incerteza não controlado estatisticamente - e que pode vir a aumentar à medida que se investigue mais a dispersão isotópica dos elementos na natureza. Este modo de lidar com as massas atómicas relativas dos elementos faz emergir a complexidade natural da química e a necessidade de se adoptar uma postura sistémica no seu estudo - uma evolução no sentido do que presentemente se chama mais latamente "ciência sob incerteza", já que a incerteza é intrínseca aos sistemas complexos. O estudo destes requer uma nova postura científica ("ciência sistémica") em que a incerteza é aceite, de raiz, como algo que limita o conhecimento. A visão sistémica contrasta com a visão reducionista do racionalismo cartesiano, base da ciência moderna e sob a qual a química foi desenvolvida de forma crescente ao longo do século $X X$, mas não é nova na química - desde logo, é bom lembrar que Mendeleiev chamou 
Sistema Periódico à Tabela Periódica dos Elementos! A visão reducionista é intrinsecamente simplista e embora a simplicidade permita maior generalidade às teorias científicas, o que tem a vantagem de facilitar a falsificabilidade (Popper), nem sempre permite captar a complexidade da natureza às vezes, com o uso, tal como sucede com as facas da cozinha, a faca de Occam fica romba. Mas, ao contrário das facas físicas, não pode ser afiada - por isso, tem de se mudar de quadro mental, para compreender mais cabalmente a natureza e limitações do reducionismo e a necessidade de mudança para uma postura sistémica.

\section{NOTAS}

Em português, utiliza-se a designação "massa atómica relativa" como tradução da designação inglesa "atomic weight" que é ainda aceite, por motivos históricos, pela IUPAC [5]. A International Organization for Standardization, já em 1992 [6], propôs como equivalente ao que se denominava por "atomic weight" (que seria uma grandeza com unidade de força) a designação "relative atomic mass" (que é uma grandeza de dimensão 1). A massa atómica relativa de um elemento é dada pela razão entre a massa média por átomo desse elemento e 1/12 da massa atómica do isótopo $\mathrm{C}-12$ do carbono. A expressão "massa atómica relativa média" corresponde à denominação inglesa "standard atomic weight".

2 Um material de referência é suficientemente homogéneo e estável em relação à propriedade especifi- cada. Foi preparado para ser adequado à utilização prevista para uma medição ou para um exame de propriedades qualitativas, com especificação da sua rastreabilidade. Os materiais de referência com valores atribuídos à grandeza para que foram destinados podem ser usados em medições precisas e em calibrações [7]. Nos pormenores técnicos dos materiais de referência isotópica fornecidos pelo IRMM ou pelo NIST [8], refere-se que estes têm uma composição elementar de pureza elevada e são isotopicamente homogéneos ao nivel do micrograma por grama.

${ }^{3}$ Em Portugal, os radioquímicos adotaram o termo período de semidesintegração para designar o tempo de meia-vida.

${ }^{4}$ O valor convencional de uma grandeza é o valor que the é atribuído por meio de acordo para uma utilização específica. Aceita-se que o valor convencional de uma grandeza tem associado uma incerteza de medição muito pequena, podendo ser zero [7]. No caso das massas atómicas relativas médias, os valores convencionais só devem ser usados nas atividades para que foram aprovados, ou seja, utilizadores do comércio e indústria.

\section{REFERÊNCIAS}

[1] M.E. Wieser, T.B. Coplen, Atomic weights of the elements 2009 (IUPAC Technical Report), Pure and Applied Chemistry 83(2) (2011) 359-396.

[2] IUPAC Gold Book. http://goldbook. iupac.org/S05907.html (conferido em 31 de maio de 2012)
[3] CIAAW. http://www.ciaaw.org/atomic_weights8.htm (conferido em 31 de maio de 2012).

[4] M. Berglund, M.E Wieser, Isotopic compositions of the elements (2009) (IUPAC Technical Report), Pure and Applied Chemistry 83(2) (2011) 397410.

[5] International Union of Pure and Applied Chemistry, Physical and Biophysical Chemistry Division, Quantities, Units and Symbols in Physical Chemistry, 3. ${ }^{\text {a }}$ ed., RSCPublishing, 2007.

[6] International Organization for Standardization, ISO Standards Handbook, Quantities and Units -Part 8: Physical chemistry and molecular physics, ISO 31-8:1992.

[7] Joint Committee for Guides in Metrology, International vocabulary of metrology - Basic and general concept and associated terms, 3. ${ }^{\text {a }}$ ed., (VIM3), JCGM 200:2012. http://www.bipm. org/en/publications/guides/vim.html (conferido em 31 de maio de 2012).

[8] IRMM - Institute for Reference Materials and Measurements (European Commission Joint Research Centre), Isotopic Reference Materials Certified by JRC-IRMM Catalogue 2008, http://irmm.jrc.ec.europa.eu/reference_materials_catalogue/catalogue/ Documents/isotopicrm_catalogue_ jun2008.pdf (conferido em 6 de junho de 2012); NIST - National Institute of Standards and Technology (U.S. Department of Commerce), Material measurement Laboratory, High-Precision Isotopic Reference Materials, http://www.nist.gov/mml/analytical/ inorganic/isotopicrms.cfm (conferido em 6 de junho de 2012).
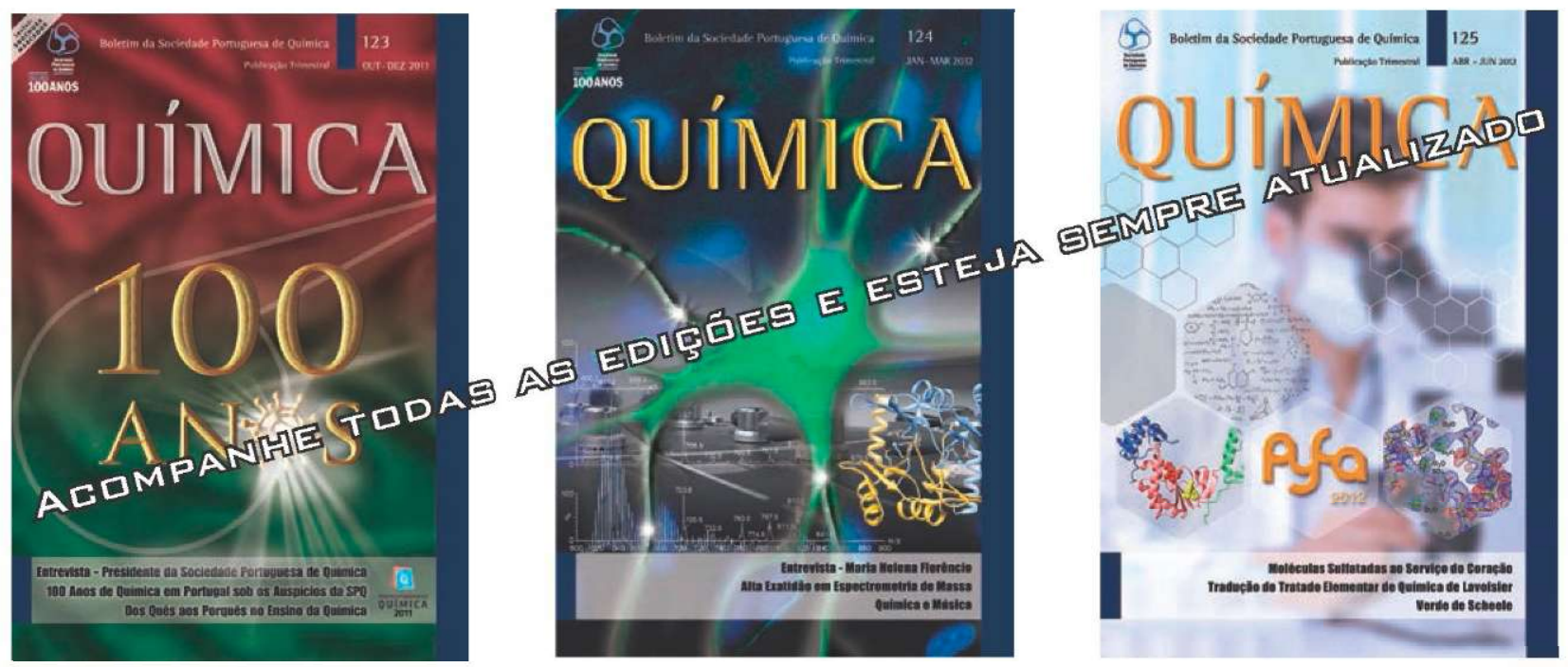


\section{$00.0^{\circ}$ \\ Chemistryviews}

Brought to you by

$\mathbb{*}_{*}^{\star}$ ChemPubSoc Europe

The best chemistry content

Exciting news, education, entertainment and multi-media

Fast track to unique articles and 16 society platforms with the new online magazine

1019:8: ChemViews $\underbrace{\star \star \star *}_{\text {Europe }}$

\section{Spot your favorite content at}

www.ChemistryViews.org 